\title{
A comparative evaluation of King Vision video laryngoscope (channelled blade), McCoy, and Macintosh laryngoscopes for tracheal intubation in patients with immobilized cervical spine
}

\author{
QE $\mathrm{Ali}^{1^{*}}, \mathrm{SH} \mathrm{Amir}^{2}, \mathrm{~S} \mathrm{Ahmad}^{3}$ \\ Professor $^{1}$, Assistant Professor ${ }^{2}$, Senior Resident ${ }^{3}$, Dept of Anesthesiology, Jawaharlal Nehru Medical \\ College, A.M.U., Aligarh, U.P., India.
}

\begin{abstract}
Background: Cervical spine immobilization results in a poor laryngeal view on direct laryngoscopy leading to difficulty in intubation. This randomized prospective study was designed to compare the laryngeal view and ease of intubation with the Macintosh, McCoy, and King Vision video laryngoscopes in patients with immobilized cervical spine.
\end{abstract}

Method: Ninety adult patients of ASA grade I-II with immobilized cervical spine using manual inline axial cervical spine stabilization technique, undergoing elective cervical surgery were enrolled. The patients were randomly allocated into three groups to achieve tracheal intubation with Macintosh (MAC group n=30), McCoy (MCC group $n=30$ ), or King Vision video laryngoscopes (KVL group). When the best possible view of the glottis was obtained, the Cormack-Lehane laryngoscopy grade and the percentage of glottic opening (POGO) score were assessed. Other measurements included the intubation time, the intubation difficulty score, and the intubation success rate. Haemodynamic parameters and any airway complications were also recorded.

Result: King Vision video laryngoscope reduced the intubation difficulty score, improved the Cormack and Lehane glottic view, and the POGO score compared with the McCoy and Macintosh laryngoscopes. The first attempt intubation success rate was also high in the King Vision video laryngoscope group. However, there were no statistically significant differences in the time required for successful intubation and the overall success rates between the devices tested. No dental injury or hypoxia occurred with either device.

Conclusion: The use of a King Vision video laryngoscope resulted in better glottis visualization, easier tracheal intubation, and higher first attempt success rate as compared to Macintosh and McCoy laryngoscopes in immobilized cervical spine patients.

Keywords: King Vision; McCoy; Macintosh; immobilized neck

\section{Introduction}

It is a significant challenge even to the most experienced anaesthesiologist to intubate patients in whom the movement of the cervical spine is not desirable or restricted.

Tracheal intubation must be performed with care in patients with cervical spine fractures or other cervical pathology to prevent cord damage. The

*Correspondence: QE Ali

E mail: qaziehsanali@gmail.com

Received: 15/12/2016

Accepted: 16/04/2017

DOI: 10.4038 /slja.v25i2.8200

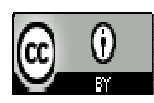

use of semi rigid cervical collar or manual inline stabilization of the cervical spine to prevent neck movements may result in poor laryngeal view on conventional laryngoscopy leading to difficulty in intubation. ${ }^{1,2}$ Several options have been mentioned by various authors for intubation in such patients, like direct laryngoscopy with the aid of a gum elastic bougie, Airway Scope, McCoy laryngoscope, fibre optic bronchoscope, C-Trach, Intubating Laryngeal Mask Airway and Bullard laryngoscope which have been used with different success rates. ${ }^{3-5}$

The McCoy laryngoscope (Penlon) is designed to elevate the epiglottis with its hinged tip and requires less neck movement during 
laryngoscopy. ${ }^{6}$ It is frequently used to facilitate tracheal intubation when the view of the glottic opening is restricted. ${ }^{7}$

The King Vision video laryngoscope is the latest in a long series of devices that provide the "perfect view" for intubation via use of video and digital technology. It has two types of blades one with channel and the other without channel. The display is an organic light emitting diode (OLED) design of surprisingly good clarity and resolution. The channelled blade requires minimum of $18 \mathrm{~cm}$ mouth opening while nonchannelled blade requires minimum $13 \mathrm{~cm}$ mouth opening. ${ }^{8}$

However, relative efficacies of these devices in comparison with the Macintosh laryngoscope have not been compared in cervical injury patients. Therefore, this randomized, prospective study was planned to compare the effectiveness of Macintosh, McCoy, and King Vision video laryngoscopes for ease of intubation in patients with immobilized cervical spine.

\section{Method}

After approval from Institutional Ethical Committee and written informed consent, 90 adult ASA grade I-II patients of cervical trauma undergoing elective cervical surgery requiring tracheal intubation as part of anaesthesia were enrolled. Patients with increased risk of pulmonary aspiration, history of difficult intubation, or anticipated airway difficulties were excluded. They were randomly assigned to three groups based on the device used for laryngoscopy. In group MAC patients Macintosh laryngoscope was used, in group MCC McCoy laryngoscope was used, and in group KVL King Vision video laryngoscope (channelled blade) was used. Randomization was based on computer-generated codes that were concealed in sequentially numbered opaque envelopes. Manual in-line stabilization of head and neck was applied in all cases during intubation to prevent neurological damage.

Each patient was uniformly premedicated with midazolam $\quad 0.025 \mathrm{mg} / \mathrm{kg}, \quad$ ondansetron $0.15 \mathrm{mg} / \mathrm{kg}$, and fentanyl $2 \mathrm{mcg} / \mathrm{kg}$ body weight intravenously. A standard anaesthetic technique was used comprising preoxygenation with $100 \%$ $\mathrm{O}_{2}$ for three minutes, induction with propofol $2 \mathrm{mg} / \mathrm{kg}$ i.v. neuromuscular blockade was achieved by using succinylcholine $1.5 \mathrm{mg} / \mathrm{kg}$. Laryngoscopy was performed one min after succinylcholine administration and intubation was carried out depending on the group to which the patient was assigned.

After achieving best possible view of the glottis, two different anaesthesiologists were asked to report (the mean values of the two were used for analysis) the vocal cord visualization using the Cormack-Lehane grading (grade 1-4) ${ }^{9}$ and the percentage of glottic opening (POGO) score $(0$ to $100 \%, 100=$ full view of glottis from anterior commissure to the inter-arytenoid notch, $0=$ even inter-arytenoid notch is not seen). If adequate glottic view for intubation was not seen to the viewers, manipulations were performed as recommended in the instruction manual of the device. The endotracheal cuffed tube of appropriate size $(7.0$ and $8.0 \mathrm{~mm}$ internal diameter for women and men, respectively) was advanced into the trachea under direct vision. Finally, the scope was removed and the breathing circuit was connected. The adequacy of ventilation was confirmed by chest auscultation and capnography. Once the intubation was complete, lungs were mechanically ventilated during the procedure and anaesthesia was maintained using $60 \%$ nitrous oxide with oxygen and isoflurane (0.8$1 \%$ ). If the first intubation attempt failed, a next attempt was made after mask ventilation for 1 minute. In each group, tracheal intubation was considered a failure if it could not be accomplished in three attempts. All intubations were performed by an experienced anaesthesiologist whose previous experience included more than 20 intubations with each laryngoscope. The number of intubation attempts, the number of optimization manoeuvers required (use of stylet, laryngeal manipulations) to aid tracheal intubation, the duration of successful intubation attempt (defined as the time from insertion of the laryngoscope to confirmation of intubation by capnography), and the intubation success rate were recorded. The intubation difficulty score ${ }^{10}$ (IDS $0=$ easy, IDS 1-5 = slight difficulty, IDS $>5=$ major difficulty in intubation) was calculated as primary outcome. Secondary end points were the time taken for laryngoscopy and intubation and the rate of successful placement of end tracheal tube into trachea. The incidence of oesophageal intubation, mucosal trauma, or 
dental injury was recorded. The heart rate (HR), ECG, oxygen saturation $\left(\mathrm{SpO}_{2}\right)$, and mean arterial pressure (MAP) were recorded at the baseline, post induction, just after tracheal intubation and at 1, 3, 5 and $10 \mathrm{~min}$ post intubation. Any episode of hypotension (MAP $<20 \%$ of baseline), bradycardia (HR $<40 \mathrm{bpm}$ ), hypertension (MAP $>20 \%$ of baseline), cardiac arrhythmia, or hypoxemia $\left(\mathrm{SpO}_{2}<90 \%\right)$ was noted.

Statistical analysis: Normally distributed data was compared using one-way analysis of variance (ANOVA). The non-parametric data were analyzed using Kruskal-Wallis analysis of variance followed by the Mann-Whitney U-test for intergroup differences. The comparisons of heart rate and blood pressure were made using repeated measures ANOVA. A pair-wise comparison of the mean values was performed by the paired $t$-test with Bonferroni correction. Qualitative or categorical variables were described as frequencies and compared with the chi-squared test or the Fisher exact test whichever was applicable. All statistical tests were two sided and were performed at a significance level of $\alpha=0.05$ and $\beta=0.2$ for an experimental design incorporating three equal sized groups. Sample size was calculated at $95 \%$ significance level and $80 \%$ power, assuming the difference of 2 in the mean intubation difficulty score. We estimated that 30 patients would be required per group, so we enrolled 136 patients as shown in Figure 1.

Table 1: Demographic data and preoperative airway assessment parameters

\begin{tabular}{|l|l|l|l|}
\hline $\begin{array}{l}\text { Parameter } \\
\text { assessed }\end{array}$ & $\begin{array}{l}\text { King vision } \\
\text { video } \\
\text { laryngoscope } \\
\text { group } \\
(\mathrm{n}=30)\end{array}$ & $\begin{array}{l}\text { McCoy } \\
\text { group } \\
(\mathrm{n}=30)\end{array}$ & $\begin{array}{l}\text { Macintosh } \\
\text { group } \\
(\mathrm{n}=30)\end{array}$ \\
\hline $\begin{array}{l}\text { Male: female } \\
\text { ratio }\end{array}$ & $25: 5$ & $27: 3$ & $26: 4$ \\
\hline $\begin{array}{l}\text { Age (years) } \\
\text { Mean } \pm \text { SD }\end{array}$ & $38.26 \pm 11.38$ & $35.53 \pm 11.74$ & $37.56 \pm 8.24$ \\
\hline $\begin{array}{l}\text { Body mass } \\
\text { index (kg/m } \\
\text { Mean } \pm \text { SD }\end{array}$ & $23.19 \pm 2.27$ & $23.61 \pm 2.29$ & $24.61 \pm 1.21$ \\
\hline $\begin{array}{l}\text { MP } \\
\text { classification } \\
\text { I/II/III/IV }\end{array}$ & $12 / 11 / 3 / 4$ & $17 / 8 / 3 / 2$ & $22 / 6 / 2$ \\
\hline ASA(status) I/II & $22 / 8$ & $20 / 10$ & $26 / 4$ \\
\hline
\end{tabular}

\section{Results}

The groups were similar with respect to demographic data and ASA physical status (Table 1). The intubation difficulty score were significantly less in the King Vision video laryngoscope group as compared with other groups $(P=0.001)$. Thirteen patients had easy intubation (IDS score $=0$ ) in the King Vision video laryngoscope group as compared to only 6 patients in the Macintosh group and 8 patients in the McCoy group (Figure 2).

Figure 2: Comparison of IDS with each laryngoscope

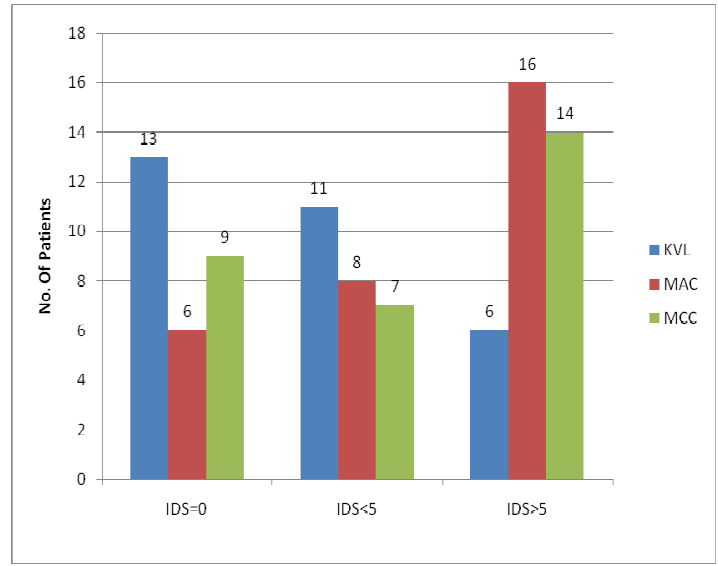

The Cormack-Lehane glottis view (Figure 3) and the POGO scores (Figure 4) were better with King Vision video laryngoscope and McCoy laryngoscopes as compared with the Macintosh laryngoscope.

Figure 3: The Cormack and Lehane score during the first attempt with each laryngoscope

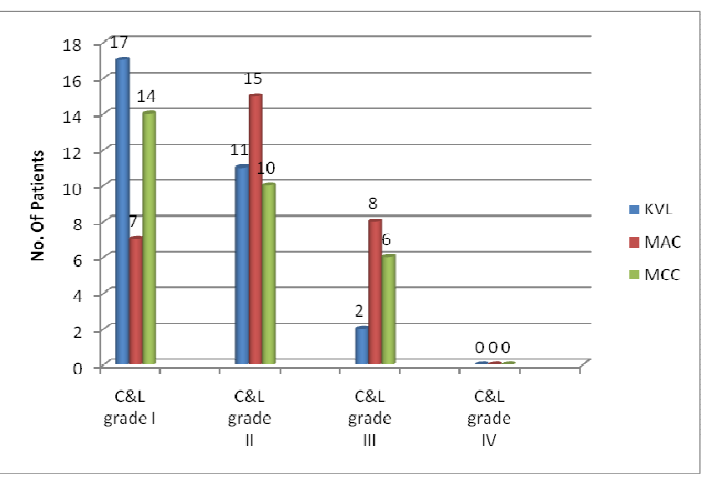

The first attempt success rate was $97 \%$ in the King Vision video laryngoscope group while $86 \%$ in the Macintosh group and $90 \%$ in the McCoy group. However, the overall success rate was comparable among the groups (Table 2). 
Figure 4: The POGO score using three devices

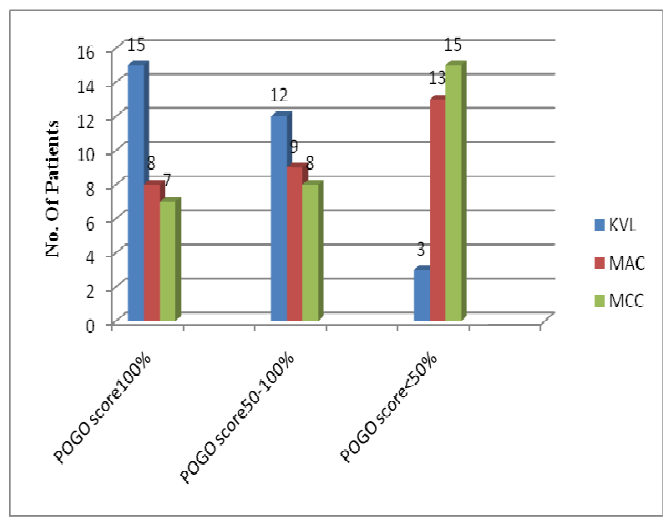

Table 2: Intubation success rate, time and airway complication

\begin{tabular}{|l|l|l|l|}
\hline $\begin{array}{l}\text { Parameter } \\
\text { assessed }\end{array}$ & $\begin{array}{l}\text { King Vision } \\
\text { video } \\
\text { laryngoscope } \\
\text { group(KVL) } \\
(\mathrm{n}=30)\end{array}$ & $\begin{array}{l}\text { McCoy } \\
\text { Group(MCC) }\end{array}$ & $\begin{array}{l}\text { Group(MAC) } \\
(\mathrm{n}=30)\end{array}$ \\
\hline $\begin{array}{l}\text { Successful } \\
\text { intubation, }\end{array}$ & $30(100 \%)$ & $30(100 \%)$ & $30(100 \%)$ \\
\hline $\begin{array}{l}\text { 1st attempt } \\
\text { success rate }\end{array}$ & $97 \%$ & $90 \%$ & $86 \%$ \\
\hline $\begin{array}{l}2^{\text {nd attempt }} \\
\text { success rate }\end{array}$ & $100 \%$ & $100 \%$ & $98 \%$ \\
\hline $\begin{array}{l}\text { No. } \\
\text { attempts } \\
1 / 2 / 3\end{array}$ & $29 / 1 / 0$ & $28 / 2 / 0$ & $27 / 2 / 1$ \\
\hline $\begin{array}{l}\text { Intubation } \\
\text { time } \\
\text { (seconds) }\end{array}$ & $26.29 \pm 11.2$ & $30.25 \pm 8.65$ & $32.5 \pm 10.6$ \\
\hline $\begin{array}{l}\text { Mucosal } \\
\text { trauma Y/N }\end{array}$ & $0 / 0$ & $1 / 0$ & $2 / 0$ \\
\hline $\begin{array}{l}\text { Oesophageal } \\
\text { intubation } \\
\text { Y/N }\end{array}$ & $0 / 0$ & $0 / 0$ & $0 / 0$ \\
\hline
\end{tabular}

There were no statistically significant differences in the time required for successful intubation $(\mathrm{P}=0.082)$ and the number of intubation attempts $(\mathrm{P}=0.072)$ between the devices tested.

The effects of laryngoscopy on heart rate (Figure 5) and blood pressure were transient.

The heart rate and mean arterial pressure (Figure 6) increased after intubation in all groups but returned to base line within $5 \mathrm{~min}$ after intubation in each group.
Figure 5: Changes in heart rate at various time intervals in the three groups.

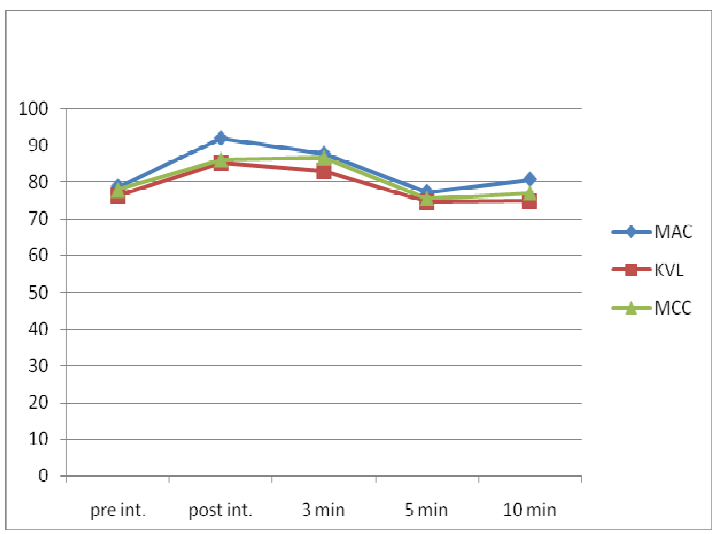

Figure 6: Changes in mean arterial blood pressure at various time intervals in the three groups.

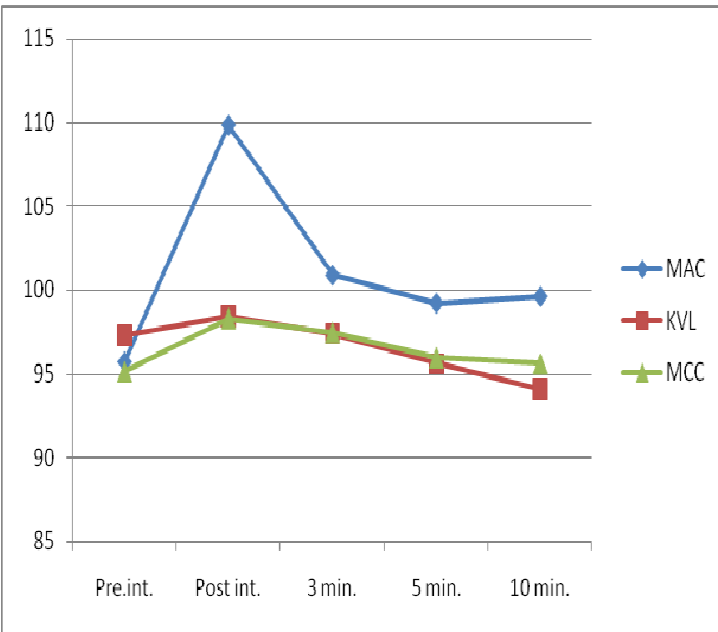

But the increase in heart rate and mean arterial pressure was less with King Vision video laryngoscope and McCoy laryngoscopes as compared to the Macintosh laryngoscope. No episode of hypoxia was reported. Mucosal trauma occurred in two patients in Macintosh group and one patient in McCoy group and none in King Vision group. None of the patients had oesophageal intubation among the three groups. No incidence of dental injury or severe airway laceration was reported with either device. 


\section{Discussion}

In the present study, the King Vision video laryngoscope reduced the intubation difficulty score and improved the glottis view, compared with Macintosh and McCoy laryngoscopes in patients with immobilized cervical spine. However, the time to intubation and overall successes rate were not improved with either laryngoscope.

In-line stabilization of cervical spine prevents head extension and neck flexion necessary for optimal alignment of the three airway axes, leading to poor exposure of vocal cords that may result in an increased incidence of Grade 3 and 4 laryngoscopic views with conventional laryngoscopy. The McCoy laryngoscope has been reported as improving the Cormack Lehane laryngoscopic view by at least one grade in $45.1 \%$ of patients wearing a rigid cervical collar, ${ }^{11}$ and in $49 \%$ of patients whose neck was stabilized with manual in-line stabilization. ${ }^{12}$ In our study, the McCoy laryngoscope improved the laryngoscopic views and reduced the intubation difficulty score as compared with the Macintosh laryngoscope but found to be less superior than the King Vision video laryngoscope. Though, lifting the epiglottis with the McCoy laryngoscope improves glottis exposure, it may require some extension of cervical spine to expose the larynx. Bilgin and Bozkurt $^{4}$ reported that McCoy requires an average intubation time of $30 \mathrm{~s}$ and results in a 94\% first attempt success rate in patients with simulated cervical spine injury. In the present study, the intubation success rate was $90 \%$ at the first attempt and intubation time was 30s with the McCoy blade. A King Vision video laryngoscope provides an indirect view of glottis without need to align oral, pharyngeal, and tracheal axes and therefore requires no cervical spine movements.

Previous studies have demonstrated that King Vision video laryngoscope improves the laryngeal view and first attempts at successful intubation when compared with the Macintosh laryngoscope in manikins with normal and anticipated difficult airways. ${ }^{13,14}$ We found that the Cormack-Lehane view and the glottis view (POGO score) were best with the King Vision video laryngoscope as compared with the other devices tested. Furthermore, the King Vision video laryngoscope required less number of optimization manoeuvres and had reduced intubation difficulty scores.

In the present study, the time to intubation with the King Vision video laryngoscope was less and comparable with McCoy and Macintosh laryngoscopes. The main problem with the King Vision video laryngoscope is fogging on the distal lens and blood and secretions in oral cavity which may reduce the image quality. Blunted haemodynamic response with the King Vision video laryngoscope shows less laryngeal manipulations and force required during intubation, thereby reducing the potential for haemodynamic stimulation.

The main limitation of this study is that the potential of observer bias exists, as it is impossible to blind the anaesthesiologist to the device being used. However, we incorporated the intubation difficulty score for the assessment of ease of intubation that incorporate multiple indices of intubation difficulty and objectively quantifies the complexity of tracheal intubations. Another limitation of our study is that we did not compare the relative efficiencies of these devices with other intubation modalities which are recommended in difficult airway scenarios, such as the intubating laryngeal mask airway, the Bullard laryngoscope, Airtraq, and glidescope. Further comparative studies are needed to determine the relative efficacies of these devices.

\section{Conclusion}

King Vision video laryngoscope is superior to Macintosh and McCoy laryngoscopes in a situation where there is restricted movement of the neck.

\section{References}

1. Goutcher CM, Lochhead V. Reduction in mouth opening with semi-rigid cervical collars. $\mathrm{Br} \mathrm{J}$ Anaesth 2005; 95: 344-8. https://doi.org/10.1093/bja/aei190

PMid: 16006487

2. Heath KJ. The effect of laryngoscopy of different cervical spine immobilisation techniques. Anesthesia 1994; 49: 843-5. https://doi.org/10.1111/j.13652044.1994.tb04254.x

3. Komatsu R, Kamata K, Hoshi I et al. Airway Scope and gum elastic bougie with Macintosh laryngoscope for tracheal intubation in patients 
with simulated restricted neck mobility. $\mathrm{Br} \mathrm{J}$ Anaesth 2008; 101: 863-9.

https://doi.org/10.1093/bja/aen288

PMid:18835885

4. Bilgin H, Bozkurt M. Tracheal intubation using the ILMA, C-Trach or McCoy laryngoscope in patients with simulated cervical spine injury. Anesthesia 2006; 61:685-91. https://doi.org/10.1111/j.13652044.2006.04706.x

PMid:16792615

5. Watts AD, Gelb AW, Bach DB, Pelz DM. Comparison of the Bullard and Macintosh laryngoscopes for endotracheal intubation of patients with a potential cervical spine injury. Anesthesiology 1997; 87: 1335-42. https://doi.org/10.1097/00000542-199712000$\underline{00012}$ PMid:9416718

6. McCoy EP, Mirakhur RK. The Levering Laryngoscope. Anesthesia 1993; 48: 516-9. https://doi.org/10.1111/j.13652044.1993.tb07075.x

7. Uchida T, Hikawa Y, Saito Y, Yasuda K. The McCoy levering laryngoscope in patients with limited neck extension. Can J Anesth 1997; 44: 674-6.

https://doi.org/10.1007/BF03015455

PMid:9187791

8. El-Tahan M, Doyle DJ, Khidr AM, Hassieb AG. Case Report: Double lumen tube insertion in a morbidly obese patient through the nonchannelled blade of the King Vision (TM) videolaryngoscope. F1000Res. 2014; 3: 129. https://doi.org/10.12688/f1000research.4481.3

9. Cormack RS, Lehane J. Difficult tracheal intubation in obstetrics. Anesthesia 1984; 39: 1105-11. https://doi.org/10.1111/j.13652044.1984.tb08932.x

10. Adnet F, Borron SW, Racine SX et al. The Intubation Difficulty Scale (IDS): proposal and evaluation of a new score characterizing the complexity of endotracheal intubation. Anesthesiology 1997; 87: 1290-7. https://doi.org/10.1097/00000542-199712000-

00005

PMid:9416711

11. Gabbott DA. Laryngoscopy using the McCoy laryngoscope after application of a cervical collar. Anesthesia 1996; 51: 812-4. https://doi.org/10.1111/j.13652044.1996.tb12606.x

12. Laurent SC, de Melo AE, Alexander-Williams JM. The use of the McCoy laryngoscope in patients with simulated cervical spine injuries. Anesthesia 1996; 51: 74-5. https://doi.org/10.1111/j.13652044.1996.tb07659.x
13. Itai $J$, Tanabe $Y$, Nishida $T$ et al. Tracheal intubation for a difficult airway using Airway scope ${ }^{\circledR}, \quad$ KingVision $\AA$ and McGRATH®: a comparative manikin study of inexperienced personnel. Critical Care 2013; 17: 159.

14. Murphy LD, Kovacs GJ, Reardon PM, Law J A. Comparison of the king vision video laryngoscope with the macintosh laryngoscope. J Emerg Med 2014; 47: 239-46. https://doi.org/10.1016/j.jemermed.2014.02.008 PMid:24742495 